\title{
Parestesia lingual: un síntoma poco común de hipoglucemia
}

\author{
Alvaro Muriel ${ }^{1}$, Nicole Chamorro ${ }^{2}$, Alin Abreu³, William Jubiz $H^{4}$.
}

${ }^{1}$ Residente de Medicina Interna, Universidad Libre, Codirector del grupo de investigación GIMI1 (grupo interinstitucional de medicina interna 1)

${ }^{2}$ Estudiante de pregrado, Universidad Libre, Semillero

de investigación, grupo de investigación GIMI1 (grupo

interinstitucional de medicina interna 1)

${ }^{3}$ Profesor de Medicina Interna, Universidad Libre.

${ }^{4}$ Profesor de Medicina Interna, Universidad Libre y Director, Centro

de Endocrinología, Metabolismo y Diabetes, Cali

Fecha de recepción: 01/05/2015

Fecha de aceptación: 25/06/2015

\section{Resumen}

Presentamos una mujer de 42 años quien consultó por parestesia lingual y ganancia de $10 \mathrm{Kg}$ de peso, sin síntomas clásicos de hipoglucemia, a quién se le encontró una glucemia en ayunas de $46 \mathrm{mg} / \mathrm{dl}$ (2,6 $\mathrm{mmol} / \mathrm{L})$ con insulina y péptido C concomitantes de $10,2 \mu \mathrm{U} / \mathrm{ml}(73,2 \mathrm{pmol} / \mathrm{L})$ y $2,14 \mathrm{ng} / \mathrm{dl}$ $(79,2 \mathrm{nmol} / \mathrm{L})$ respectivamente. Hallazgos similares fueron encontrados en una segunda ocasión. La resonancia magnética del páncreas mostró una lesión de 1,7 x 1,3 cm dependiente del reborde superior del cuerpo, la cual fue extirpada vía laparoscopia. Patología reveló un tumor neuroendocrino con inmunohistoquímica positiva para insulina, cromogranina y sinaptofisina. La parestesia lingual desapareció y la glucosa se normalizó. La tríada de Whipple no siempre está presente en pacientes con hipoglucemia, mientras que la parestesia lingual debe considerarse para la evaluación de estos pacientes.

Palabras clave: parestesia lingual, hipoglucemia, insulinoma.

\section{Abstract}

We report on a 42 years old female who consulted because of lingual paresthesia and $10 \mathrm{~kg}$ weight gain but without classic symptoms of hypoglycemia, who had a fasting blood glucose of 46 $\mathrm{mg} / \mathrm{dl}(2.6 \mathrm{mmol} / \mathrm{L})$ with a concomitant insulin a C-peptide of 10.2 $\mu U / \mathrm{ml}(73.2 \mathrm{pmol} / \mathrm{L})$ and $2.14 \mathrm{ng} / \mathrm{dl}(79.2 \mathrm{nmol} / \mathrm{L})$ respectively. Similar findings were obtained on a second occasion. Magnetic resonance of the pancreas revealed a $1.7 \times 1.3 \mathrm{~cm}$ lesion dependent of the superior border of the body which was removed by laparoscopy. Pathology showed a neuroendocrine tumor with positive immmu- nohistochemistry for insulin, chromogranin and synaptophysin. Lingual paresthesia disappeared and blood glucose was normalized. Patients with lingual paresthesia should be evaluated for hypoglycemia even in the absent of a classic Whipple triad.

\section{Introducción}

La triada propuesta por Whipple en $1938^{(1)}$ está constituida por síntomas adrenérgicos o neuroglucopénicos, asociados a un descenso en la glucosa sanguínea por debajo de lo normal y normalización de los anteriores con la administración de glucosa. Se ha sugerido que la triada esté presente para sospechar la presencia de hipoglucemia. Presentamos una paciente en quien la parestesia lingual como causa de consulta fue la clave para el diagnóstico de insulinoma, extirpación de la lesión y desaparición de los síntomas.

\section{Presentación del caso}

Se trata de una mujer de 42 años quien consultó por parestesia lingual y en la región peribucal, parestesias de manos, somnolencia y ganancia de $10 \mathrm{Kg}$ de peso. El índice de masa corporal (IMC) era de 30 y una glucemia ocasional estaba en 61 $\mathrm{mg} / \mathrm{dl}$ (3,4 mmol/L). El examen físico, incluyendo signos vitales, no mostraba alteraciones. Fue hospitalizada para evaluación de posible hipoglucemia. La prueba de ayuno fue suspendida a las 14 horas por la aparición de los síntomas antes mencionados y las mediciones en sangre mostraron una glucosa de $46 \mathrm{mg} / \mathrm{dl}$ (2,6 mmol/L), insulina $10,2 \mu \mathrm{U} / \mathrm{ml}(73,2 \mathrm{pmol} / \mathrm{L})$, péptido $\mathrm{C}$ de 2,14 ng/dl (79,2 nmol/L) y relación insulina/glucosa de 0,22. La prueba fue repetida con hallazgos similares: Glucosa $47 \mathrm{mg} / \mathrm{dl}$ (2,6 mmol/L), insulina $14,1 \mu \mathrm{U} / \mathrm{ml}(101,2 \mathrm{mmol} / \mathrm{L})$, péptido $\mathrm{C}$ 2,14 ng/dl (79,2 nmol/L) y relación insulina/glucosa de 0,3. La resonancia magnética nuclear de abdomen mostró una lesión de 1,7 x 1,3 cm dependiente del borde superior del cuerpo del páncreas con las características de insulinoma (figura 1). La exploración pancreática por vía laparoscopia reveló un tumor de 2,0 cm, el cual fue extirpado (figura 2). La inmunohistoquímica del tumor fue positiva para insulina, cromogranina y sinaptofisina (figura 3). Los síntomas que motivaron la consulta de la paciente desaparecieron el día siguiente de la cirugía y la glucosa se mantuvo en $85 \mathrm{mg} / \mathrm{dl}(4,7 \mathrm{mmol} / \mathrm{L})$. 
Figura 1. Resonancia magnética de la lesión pancreática demostrada por la flecha

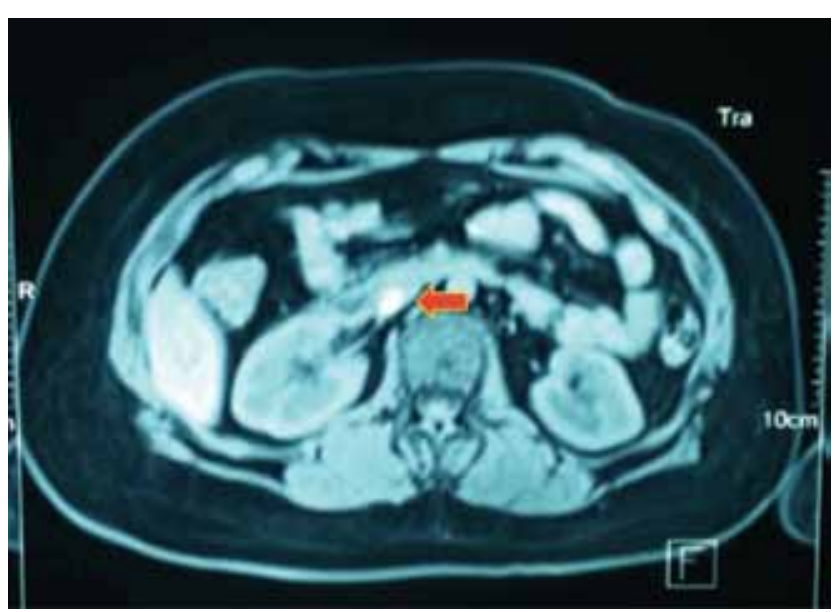

Figura 2. Tumor de $2,0 \mathrm{~cm}$, el cual fue extirpado

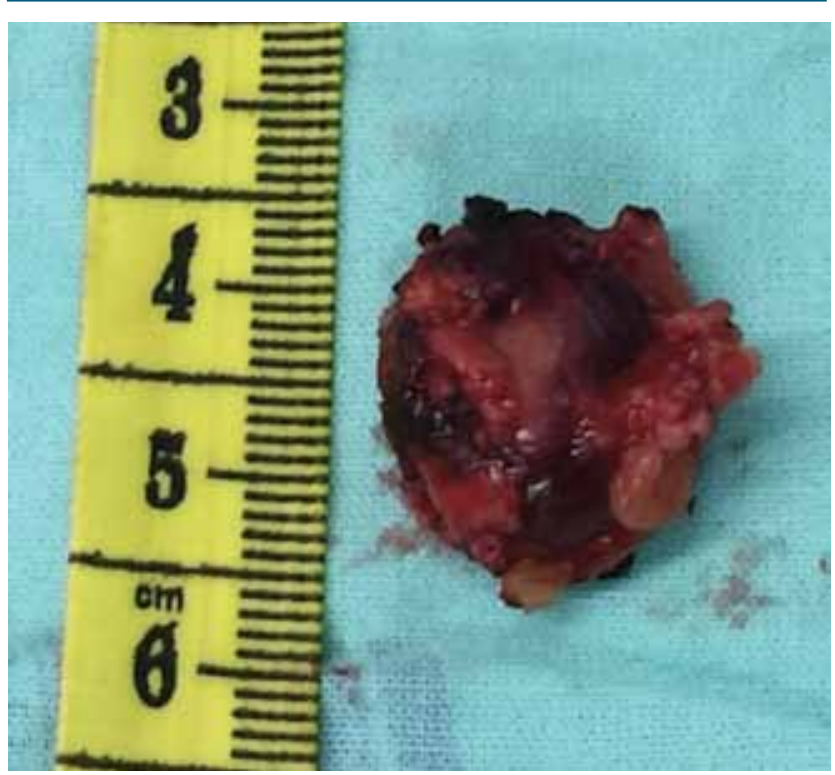

Figura 3. Inmunohistoquímica del tumor pancreático demostrando reacción para insulina

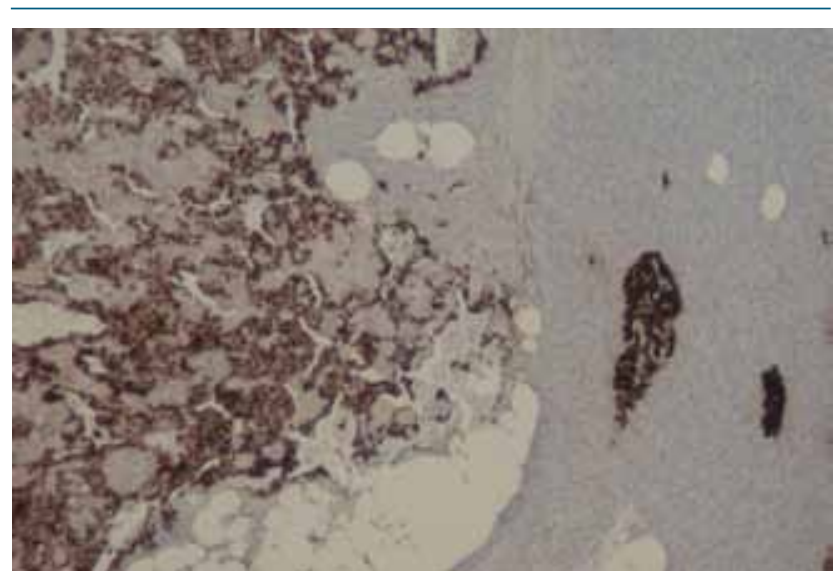

\section{Discusión}

Nuestra paciente representa una de las dificultades que se encuentra en el diagnóstico de hipoglucemia. No es común pensar en hipoglucemia cuando un paciente consulta por parestesia lingual. En la serie más grande de casos de la Clínica Mayo ni siquiera se menciona como una manifestación de hipoglucemia ${ }^{(2,3)}$.

Cabe destacar que, aunque las parestesias linguales no son patognomónicas de la hipoglucemia, se ha evidenciado en otros reportes de casos precisamente en pacientes de sexo femenino quienes refirieron días antes de su consulta esta manifestación ${ }^{(4)}$.

Lo que sí es común es la ganancia de peso como lo demuestra nuestra paciente. El insulinoma es una verdadera causa de obesidad endocrina, la cual se debe al aumento en el consumo de alimentos para aliviar los síntomas de hipoglucemia en presencia del exceso de insulina, la cual promueve la lipogénesis.

Es difícil decidir cuándo evaluar pacientes para diagnosticar la presencia de tumores pancreáticos secretores de insulina. En primer lugar hay dudas sobre la definición de hipoglucemia ya que niveles de hasta $30 \mathrm{mg} / \mathrm{dl}$ han sido informados en personas normales ${ }^{(5)}$. Por otro lado, no hay acuerdo en cuanto a los criterios para sospechar hipoglucemia. Placzkowski y colaboradores $^{(3)}$ han sugerido valores de glucosa de $40 \mathrm{mg} /$ dl con insulina plasmática $>6 \mu \mathrm{U} / \mathrm{ml}$ y péptido $\mathrm{C}>6 \mathrm{ng} / \mathrm{dl}$ para establecer el diagnóstico, mientras que la guía de práctica clínica de la Sociedad de Endocrinología de los Estados Unidos sugiere una glucosa $<55 \mathrm{mg} / \mathrm{dl}(3,0 \mathrm{nmol} / \mathrm{L})$ con insulina $>3,0 \mu \mathrm{U} / \mathrm{ml}(18 \mathrm{pmol} / \mathrm{L})$ y péptido $\mathrm{C}>0,9 \mathrm{ng} / \mathrm{ml}(0,2 \mathrm{nmol} / \mathrm{L})$ para establecer el diagnóstico de insulinoma ${ }^{6}$. Utilizando los criterios de la Clínica Mayo en nuestro paciente no hubiéramos hecho el diagnóstico correcto, mientras que con los criterios de la Sociedad de Endocrinología de EE.UU. sí hubiéramos acertado. La relación de glucosa/insulina mayor de 0,3 ha sido sugerida como característica de insulinoma ${ }^{(2)}$ pero en nuestro paciente los valores estuvieron por debajo de esa cifra.

Agradecimientos: Los autores agradecen a los doctores María Victoria Pérez por su participación en la extirpación del tumor y Harold Cuello quién realizó la inmunohistoquímica del tumor.

\section{Referencias}

1. Whipple. J InternatChir. 1938; 3: 237-276.

2. Cryer P 2001. The prevention and correction of hypoglycemia. In: Jefferson L, Cherrington A, Goodman H eds Handbook of Physiology ; Section7, the endocrine system. Volume 2 . The endocrine pancreas and regulation of metabolism. New York : Oxford University Press; 1057-1092.

3. Service FJ, Dale AJ, Elveback LR et al. Insulinoma. Clinical and diagnostic features of 60 consecutive cases. Mayo Clinic proc 1976 Jul; 51(7): 417-429.

4. Jácome Roca A, Espinosa H, Echeverry G, Escallón A, Baena M. Insulinoma, demostración de hiperinsulinismo y localización preoperatoria: Manejo Quirurgico. Univmed 1983; 25 (1): 28-35.

5. Placzkowski KA, Vella A, Thompson GB et al. Secular trends in the presentation and management of functioning insulinoma at the Mayo Clinic, 19872007. J ClinEndocrinolMetab 2009 Apr; 94(4): 1069-1073.

6. Cryer PE, Axelrod L, Grossman AB et al. Evaluation and management of adult hypoglycemic disorders: an Endocrine Society Clinical Practice Guideline. J ClinEndocrinolMetab 2009 Mar; 94(3): 709-728. 